\title{
A Comparative Study of Nanosized Gold and Copper Catalysts on Y- doped Ceria for the Water-Gas Shift Reaction
}

\author{
Tatyana Tabakova ${ }^{1}$, Ivan Ivanov ${ }^{1}$, Janusz W. Sobczak ${ }^{2}$, Wojciech Lisowski ${ }^{2}$, Zbigniew Kaszkur ${ }^{2}$, Rodolfo \\ Zanella $^{3}$, Petya Petrova ${ }^{1}$, Yordanka Karakirova ${ }^{1}$, Lyuba Ilieva ${ }^{1}$ \\ ${ }^{1}$ Institute of Catalysis, Bulgarian Academy of Sciences \\ Acad. G. Bonchev Str. Bl. 11, 1113 Sofia, Bulgaria \\ tabakova@ic.bas.bg; bogoev@ic.bas.bg; petia@ic.bas.bg; daniepr@ic.bas.bg; luilieva@ic.bas.bg \\ ${ }^{2}$ Institute of Physical Chemistry, Polish Academy of Sciences \\ Kasprzaka 44/52, 01-224 Warsaw, Poland \\ jsobczak@ichf.edu.pl; wlisowski@ichf.edu.pl; zkaszkur@ichf.edu.pl \\ ${ }^{3}$ Instituto de Ciencias Aplicadas y Tecnología, Universidad Nacional Autónoma de México \\ 04510 México, Mexico \\ rodolfo.zanella@icat.unam.mx
}

\begin{abstract}
The increasing demands for high-purity hydrogen for fuel-cell processing systems caused a renewed interest in the watergas shift reaction. This work aims to analyse the suitability of gold- and copper-based catalysts for efficient upgrading the purity of hydrogen for small-scale applications. New catalytic materials were developed by deposition of nanosized gold or copper oxide particles on ceria doped by various amount of $\mathrm{Y}_{2} \mathrm{O}_{3}(1.0,2.5$ and $5.0 \mathrm{wt} . \%)$. A favourable effect of the ceria modification on the WGS activity of gold/ceria catalysts was observed. Superior CO conversion degrees (> $95 \%$ ) were achieved in the range $180-220{ }^{\circ} \mathrm{C}$. The similarity in the catalytic activity was explained with the insignificant differences in the gold particle size among all gold-based samples. Surprisingly, copper-based catalysts exhibited decreased activity at increasing amount of $\mathrm{Y}_{2} \mathrm{O}_{3}$ in the composition of ceria supports. A characterization of the catalysts by $\mathrm{N}_{2}$ physisorption, XRD, HRTEM/HAADF, XPS, EPR and $\mathrm{H}_{2}$-TPR was carried out to reveal the effect of dopant amount on the WGS activity. The differences in the WGS performance were related to the catalysts reducibility, e.g. the availability of oxygen species with enhanced mobility. The analysis of structure-property-WGS activity relations proved to be a reliable tool for the improvement of catalyst performance by rational changes in the catalyst composition and structure.
\end{abstract}

Keywords: Hydrogen production, Water-gas shift reaction, Nanogold catalysts, Copper catalysts, Ceria, Y-doped ceria.

\section{Introduction}

Water-gas shift (WGS) reaction has a long historical application. Today it is already a well-established industrial process for generation of hydrogen and additional increase of its concentration in the gas mixtures obtained by processes utilizing coal, petroleum or biomass resources. Presently, the emerging hydrogen economy demonstrates a very high potential of fuel cells to replace the internal-combustion engine in vehicles and to supply power in stationary and portable devices, due to their high-energy efficiency, cleanness, and fuel flexibility. Roberts et al. consider that hydrogen and fuel cell technologies are very close to the commercial implementation at a meaningful scale and anticipate the realization within the end of this decade [1]. In this context, the WGS reaction attracted renewed interest owing to the increasing demands for high-purity hydrogen. Because of safety and technical constraints, the traditional commercial catalysts for large-scale hydrogen production $\left(\mathrm{Cu} / \mathrm{ZnO}\right.$-based and $\left.\mathrm{Fe}_{2} \mathrm{O}_{3}-\mathrm{Cr}_{2} \mathrm{O}_{3}\right)$ are not suitable for fuel processors. These catalysts require special activation procedures before use; they are pyrophoric, intolerant of poisons, susceptible to oxidation and condensation. Additionally, some technical issues like small catalyst volume and weight, reduced start-up time, stability under steady state and transient conditions impose new goals and challenges for design of WGS catalysts. Developing well-performing and stable catalysts is of primary importance for efficient upgrading purity of hydrogen for small-scale applications such as residential fuel cells or on-board hydrogen generators. Gold-based catalysts demonstrated very attractive performance for WGSR at low temperature [2]. Following the great success of the Haruta's discovery of remarkably high CO oxidation activity of goldbased catalysts, in 1995 Andreeva and colleagues presented the earliest report on applicability of oxide-supported gold 
catalysts for CO removal from hydrogen feed by the WGS reaction [3]. In addition to the role of highly dispersed gold particles, this study highlighted the crucial role of the support nature. Ceria is one of the most employed support for gold nanoparticles in the low-temperature WGS reaction, due to its unique combination of the ability to shift easily between reduced and oxidized state $\left(\mathrm{Ce}^{4+} / \mathrm{Ce}^{3+}\right)$ and an elevated oxygen storage capacity [4,5]. Additionally, modification of ceria by doping with suitable metals can strongly improve redox properties, in particular oxygen vacancies formation, thus affecting the WGS performance [6,7].

Copper is widely used as an active component in commercially applicable WGS catalysts for large scale hydrogen production due to its activity at low temperatures and lower cost in comparison with the noble metals. The present work is focused on understanding the relationship between the structural features and the properties of gold and copper catalysts supported on Y-doped ceria and their WGS behaviour. The effect of the amount of $\mathrm{Y}_{2} \mathrm{O}_{3}$ dopant was investigated.

\section{Experimental \\ 2.1. Samples preparation}

Yttrium-doped ceria supports $\left(\mathrm{Y}_{2} \mathrm{O}_{3}=1.0,2.5\right.$ and 5.0 wt.\%) were prepared by coprecipitation method. The synthesis procedure included coprecipitation of mixed solutions of $\mathrm{Ce}\left(\mathrm{NO}_{3}\right)_{3} \cdot 6 \mathrm{H}_{2} \mathrm{O}$ and $\mathrm{Y}\left(\mathrm{NO}_{3}\right)_{3} \cdot 6 \mathrm{H}_{2} \mathrm{O}$ at a desired ratio with a solution of $\mathrm{K}_{2} \mathrm{CO}_{3}$ at constant $\mathrm{pH}=9.0$ and at a temperature of $60{ }^{\circ} \mathrm{C}$. The precipitates were aged for $1 \mathrm{~h}$ at the same temperature, filtered and washed until complete removal of $\mathrm{NO}_{3}{ }^{-}$ions. Further, the washed precipitates were dried at $80{ }^{\circ} \mathrm{C}$ in vacuum and calcined at $400{ }^{\circ} \mathrm{C}$ in air for $2 \mathrm{~h}$. The samples prepared by following this procedure were named $\mathrm{xYCe}\left(\mathrm{x}=1,2.5\right.$ and 5, denoting the wt.\% amount of $\left.\mathrm{Y}_{2} \mathrm{O}_{3}\right)$.

The gold- and copper-based catalysts were prepared by deposition-precipitation using $\mathrm{HAuCl}_{4}$ (Alfa Aesar) or $\mathrm{Cu}\left(\mathrm{NO}_{3}\right)_{2} .3 \mathrm{H}_{2} \mathrm{O}$ (Fluka) as gold and copper precursor, respectively. The syntheses were carried out at $\mathrm{pH} 7.0$ and $60{ }^{\circ} \mathrm{C}$ using $0.2 \mathrm{M}$ solution of $\mathrm{K}_{2} \mathrm{CO}_{3}$ as precipitant. Prior to the gold or $\mathrm{CuO}$ deposition, each $\mathrm{Y}$-doped ceria support was activated under stirring in an ultrasound disintegrator. The precipitates were filtered, carefully washed, dried under vacuum at $80{ }^{\circ} \mathrm{C}$ and calcined in air at $400{ }^{\circ} \mathrm{C}$ for $2 \mathrm{~h}$. The samples were denoted as $\mathrm{Au} / \mathrm{xYCe}$ or $\mathrm{Cu} / \mathrm{xYCe}$, depending on the amount of Y-dopant. The content of $\mathrm{Au}$ and $\mathrm{Cu}$ metals was adjusted to $3 \mathrm{wt} \%$ from economical point of view. In case of copper-based catalysts, additionally the low loading targets avoiding of undesired agglomeration of copper particles during the catalytic tests.

Undoped $\mathrm{Au} / \mathrm{CeO}_{2}$ and $\mathrm{CuO} / \mathrm{CeO}_{2}$ (denoted as $\mathrm{Au} / \mathrm{Ce}$ and $\mathrm{Cu} / \mathrm{Ce}$, respectively) were used as reference catalysts. Both samples were prepared by the same deposition-precipitation method, using the conditions described above.

\subsection{Samples characterization}

The specific surface areas of the catalysts were determined by the BET equation using Quantachrome Instruments NOVA 1200e (USA) at $-196{ }^{\circ} \mathrm{C}$ in the pressure range $0.05-0.3 \mathrm{p} / \mathrm{po}$. Prior to the measurements, the samples were outgassed at $200{ }^{\circ} \mathrm{C}$ for 90 min under vacuum.

A D5000 diffractometer (Bruker AXS), with $\mathrm{Cu}$ sealed tube operating at $40 \mathrm{kV}$ and $40 \mathrm{~mA}$ was used for X-ray powder diffraction (XRD) measurements. The data analysis was performed with PeakFit program (Jandel Scientific) fitting XRD profiles to K $\alpha$ 1,2 doublets having PEARSON VII analytical form. The estimation of gold particles crystal size was done by considering the full width at half maximum (FWHM) of the strongest (111) reflection. The average crystal size of ceria was calculated on the basis of a Williamson-Hall plot type analysis and 14 measured reflections of ceria fcc lattice $[8,9]$.

High resolution transmission electron microscopy (HRTEM) and Z-contrast (high angle annular dark field) observations of gold-based samples were carried out in a JEM 2010 FasTem analytical microscope. The mean size of gold particles $\left(D_{A u}\right)$ was calculated by the formula $D_{A u}=\sum n_{i} D_{i} / \sum n_{i}$ where $n_{i}$ is the number of particles with diameter $D_{i}$.

The X-ray photoelectron spectroscopy (XPS) measurements were performed using PHI 5000 VersaProbe (ULVACPHI, Japan) spectrometer with monochromatic Al-Ka radiation $(\mathrm{h} v=1486.6 \mathrm{eV})$. The high-resolution spectra of elements were recorded with the energy step $0.1 \mathrm{eV}$ at the pass energy $23.5 \mathrm{eV}$ using the X-ray source operating at the following conditions: $100 \mu \mathrm{m}$ spot size, $25 \mathrm{~W}$ and $15 \mathrm{kV}$. The studied samples were pressed into thin wafers and degassed 
in a load lock chamber. The XPS data were evaluated by CasaXPS software and set of sensitivity factors supplied by PHI. The Shirley background subtraction and a Gaussian-Lorentzian peak shape character were used for the spectra deconvolution. The charging effects corrections were performed by adjusting the Ce $3 \mathrm{~d}_{3 / 2}$ peak to a binding energy (BE) of $916.65 \mathrm{eV}$ $[10,11]$.

The electron paramagnetic resonance (EPR) spectra of Cu-based samples were recorded as a first derivative of the absorption signal of an JEOL JES-FA 100 EPR spectrometer at low temperature $\left(-150{ }^{\circ} \mathrm{C}\right)$. The spectrometer is equipped with a standard TE011 cylindrical resonator and operating in X-band frequency $(9.5 \mathrm{GHz})$. The investigated samples were placed in a special quartz tube, which was fixed in the centre of the EPR cavity. The EPR spectra were recorded at the following conditions: modulation frequency $100 \mathrm{kHz}$, microwave power $1 \mathrm{~mW}$, modulation amplitude $0.4 \mathrm{mT}$, sweep 100 $\mathrm{mT}$, time constant $0.1 \mathrm{~s}$ and sweep time 2 min.

The $\mathrm{H}_{2}$-temperature programmed reduction $\left(\mathrm{H}_{2}\right.$-TPR) measurements were performed in a set-up described elsewhere [12]. The reduction of the samples was carried out with a mixture $\left(10 \% \mathrm{H}_{2}-\mathrm{Ar}\right)$ dried over a molecular sieve $5 \mathrm{~A}\left(-40{ }^{\circ} \mathrm{C}\right)$, at a flow rate of $24 \mathrm{ml} \mathrm{min}^{-1}$, under linearly increasing temperature at a rate of $15^{\circ} \mathrm{C} \mathrm{min}^{-1}$. The sample amount $(0.05 \mathrm{~g})$ was chosen based on a criterion proposed by Monti and Baiker [13].

\subsection{WGS activity measurements.}

The WGS activity tests were carried out in a flow reactor at atmospheric pressure over a temperature range 140 - 350 ${ }^{\circ} \mathrm{C}$. The reactant gas mixture contained 3.37 vol. \% CO, 25.01 vol. $\mathrm{H}_{2} \mathrm{O}$ and 71.62 vol. \% Ar. The concentration of water vapor in the gas mixture was controlled by Syringe pump (RAZEL model R-99) with $10 \mathrm{~cm}^{3}$ syringe for very accurate flow. The experimental conditions were: catalyst bed volume $=0.5 \mathrm{~cm}^{3}(0.63-0.80 \mathrm{~mm}$ pellets $)$, gas-hour space velocity $=4000 \mathrm{~h}^{-}$

1. The content of $\mathrm{CO}$ at the reactor outlet was measured with an Uras $3 \mathrm{G}$ (Hartmann\&Braun AG) gas analyser. The degree of $\mathrm{CO}$ conversion was calculated on the basis of inlet and outlet $\mathrm{CO}$ concentration.

\section{Results and discussion}

\subsection{Catalyst characterization}

The specific surface areas $\left(\mathrm{S}_{\mathrm{BET}}\right)$ of the studied catalysts are summarized in Table 1. A tendency of decreased $\mathrm{S}_{\mathrm{BET}}$ values was observed by increasing the yttrium oxide content.

The X-ray patterns of the catalysts consist of reflections corresponding to the face-centered cubic fluorite structure of $\mathrm{CeO}_{2}$. The presence of the $\mathrm{Y}_{2} \mathrm{O}_{3}$ phase was not observed. The main reflection of metallic $\mathrm{Au}(111)$ at $2 \theta=38.2^{\circ}$ was discernible. The average size of ceria and gold particles was calculated on the basis of the FWHM of the peaks registered in the XRD patterns (Table 1). The ceria average size decreased at increasing amount of dopant in two series of samples, indicating slight effect of $\mathrm{Y}_{2} \mathrm{O}_{3}$ addition on the ceria crystallization. Similar gold particles size was found in all samples. The lack of XRD reflections corresponding to $\mathrm{CuO}$ crystal phase $\left(2 \theta=35.6^{\circ}, 38.8^{\circ}\right.$ and $61.6^{\circ}$, JCPDS $\left.72-0629\right)$ suggested high dispersion of $\mathrm{CuO}$ particles.

Table 1: BET surface area $\left(\mathrm{S}_{\mathrm{BET}}\right)$, lattice parameter $\left(\alpha_{\text {ceria }}\right)$ and average particles size of ceria estimated by XRD; average size of gold particles estimated by XRD and HRTEM/HAADF.

\begin{tabular}{|c|c|c|c|c|c|}
\hline Catalyst & $\mathrm{S}_{\mathrm{BET}}$ & $\begin{array}{c}\alpha \\
\left(\mathrm{CeO}_{2}\right) \\
\mathrm{nm}\end{array}$ & $\begin{array}{c}\text { Average size } \\
\text { of } \mathrm{CeO}_{2} \\
\mathrm{~nm}\end{array}$ & $\begin{array}{c}\text { Average size of } \\
\mathrm{Au} / \mathrm{Cu} \text { by XRD } \\
\mathrm{nm}\end{array}$ & $\begin{array}{c}\text { Average size of } \\
\text { Au/Cu by HRTEM } \\
\mathrm{nm}\end{array}$ \\
\hline $\mathrm{Au} / \mathrm{Ce}$ & 102.4 & 0.5417 & 5.7 & 4.1 & 3.0 \\
\hline $\mathrm{Au} / 1 \mathrm{YCe}$ & 90.0 & 0.5417 & 8.1 & 6.0 & 3.2 \\
\hline $\mathrm{Au} / 2.5 \mathrm{YCe}$ & 88.7 & 0.5413 & 5.1 & 5.3 & 2.2 \\
\hline $\mathrm{Au} / 5 \mathrm{YCe}$ & 82.4 & 0.5419 & 4.3 & 5.5 & 2.4 \\
\hline $\mathrm{Cu} / \mathrm{Ce}$ & 104.0 & 0.5409 & 8.2 & n.d. & n.m. \\
\hline $\mathrm{Cu} / 1 \mathrm{YCe}$ & 102.0 & 0.5408 & 8.1 & n.d. & n.m \\
\hline
\end{tabular}




\begin{tabular}{|c|c|c|c|c|c|}
\hline $\mathrm{Cu} / 2.5 \mathrm{YCe}$ & 100.0 & 0.5407 & 6.6 & n.d. & n.m. \\
\hline $\mathrm{Cu} / 5 \mathrm{YCe}$ & 98.0 & 0.5407 & 5.8 & n.d. & n.m \\
\hline
\end{tabular}

It is interesting to analyse the values of ceria lattice parameter. In case of gold-based catalysts, the unit cell are slightly higher than that of stoichiometric $\mathrm{CeO}_{2}(0.541 \mathrm{~nm})$ [14]. The replacement of Ce by $\mathrm{Y}$ ions is not a relevant reason, because of the known similarity of the ionic radii $\left(0.97 \AA\right.$ for $\mathrm{Ce}^{4+}$ and $1.02 \AA$ for $\mathrm{Y}^{3+}$ in eight-fold coordination). However, considering the larger size of $\mathrm{Ce}^{3+}(1.14 \AA)$ in comparison with $\mathrm{Ce}^{4+}$ it could be hypothesised that higher values of $\alpha$ is due to Au-induced modification of $\mathrm{CeO}_{2}$. In agreement with previous FTIR study, nanosized gold particles caused reduction of $\mathrm{Ce}^{4+}$ and formation of uncoordinated (cus) sites near the very small gold clusters [15]. Just the opposite effect was observed over copper-based samples. Lower values of the ceria cell parameter could be attributed to a decreased $\mathrm{Ce}^{3+}$ concentration and depletion of oxygen vacancies.

It is well-known the important role of gold particles size on the WGS activity [16]. Detailed information on the gold dispersion was provided by HRTEM/HAADF measurements (Table 1). The measurement of more than 2000 particles obtained by Z-contrast observations allowed establishing the histograms of the gold particle sizes (Fig. 1). Very similar values were obtained and this finding will be discussed for explanation of the WGS activity.
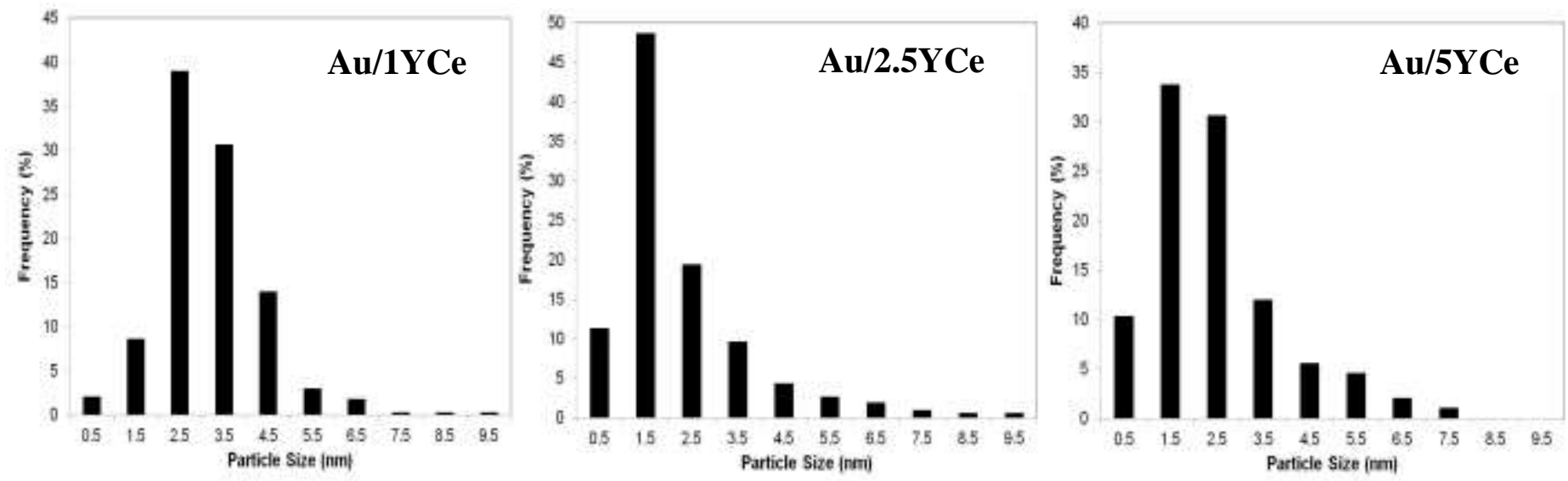

Fig. 1. Size distribution of the gold particles in gold-base catalysts.

The oxidation state of the components formed at the surface of the catalysts was investigated by XPS. The evaluation of the spectral analysis of Ce3d XP spectra showed the contributions from both $\mathrm{Ce}^{4+}$ and $\mathrm{Ce}^{3+}$ with very similar values of binding energies. Focusing on the presence of $\mathrm{Ce}^{3+}$ it was observed higher atomic concentrations for all gold-based catalysts in comparison with copper-based ones. Special attention was paid to both Au/2.5YCe and Cu/2.5YCe samples because of their catalytic behaviour that will be discussed later. Among two series of catalysts, a lower $\mathrm{Ce}^{3+}$ surface concentration was observed for these two samples being the lowest for copper-based one, in particular $12.1 \%$ and 17.7 $\%$ for gold-based analogue. This result could be attributed to the specific properties of ceria support doped with $2.5 \mathrm{wt} . \%$ $\mathrm{Y}_{2} \mathrm{O}_{3}$, namely $2.5 \mathrm{YCe}$. Recently, an investigation of Au/Y-doped ceria catalysts for WGSR was reported [17]. Based on TPR and $\mathrm{O}_{2}$ temperature-programmed desorption measurements, it was demonstrated the highest capacity of the $\mathrm{Au} / 2.5 \mathrm{YCe}$ catalyst to keep surface oxygen stronger bonded which led to diminished surface oxygen mobility. The Au4f XP spectra were fitted successfully with two components, which indicated the predominant presence of gold in metallic state (BE $84.2-84.4 \mathrm{eV}$ ) and small portion of positively charged gold states. Concerning oxidation state of copper species in copper-based catalysts, usually, the fitting of $\mathrm{Cu} 2 \mathrm{p}$ spectra shows a component at about $933 \mathrm{eV}$ along with the shake-up peaks in the range $938-945 \mathrm{eV}$, that are characteristic of $\mathrm{Cu}(\mathrm{II})$ [18]. However, any lower energy component related to $\mathrm{Cu}(\mathrm{I})$ was not registered probably due to the very low $\mathrm{Cu} / \mathrm{Ce}$ ratios. 
Additional insights on the nature of copper species were provided by EPR study. Commonly, a hyperfine structure due to the coupling between the electron spin and the nuclear spin of the $\mathrm{Cu}^{2+}$ ions $(\mathrm{S}=1 / 2, \mathrm{I}=3 / 2)$ with four parallel and four perpendicular hyperfine components is observed in the EPR spectrum due to the presence of $\mathrm{Cu}^{2+}$ ions. In the present study, the spectrum of $\mathrm{Cu} / \mathrm{Ce}$ included superposition of a broad isotropic signal, centred at $\mathrm{g}=2.1154$ and a signal with very poorly resolved hyperfine structure. The registration of broad signal could be explained by dipolar broadening effects due to an interaction between neighbouring paramagnetic $\mathrm{Cu}^{2+}$ ions located in a $\mathrm{CuO}$-containing aggregates. The hyperfine structure indicated availability of small number isolated $\mathrm{Cu}^{2+}$ ions with axial symmetry. The spectra of all $\mathrm{Cu} / \mathrm{xYCe}$ catalysts have similar spectral features with better visible hyperfine splitting. The hyperfine structure in parallel orientation with $\mathrm{g}_{\mathrm{II}}=2.32$, $\mathrm{A}_{\mathrm{II}}=12.9 \mathrm{mT}$, and unresolved hyperfine splitting in the perpendicular range was assigned to $\mathrm{Cu}^{2+}$ monomers in octahedral sites with a tetragonal distortion [19]. A trend of slight decrease of the line width of EPR signal was detected by increasing the yttrium concentration. Usually such effect resulted from a decrease of the copper oxide clusters size. The same observation for decreasing ceria particles size was already reported based of XRD calculations (Table 1). The typical signal for $\mathrm{Cu}^{2+}$ ions was no more visible in the spectra of the samples after WGS catalytic tests, implying reduction of $\mathrm{Cu}^{2+}$ and appearance of EPR silent copper species.

The $\mathrm{H}_{2}$-TPR is a very suitable method for study of the ceria-based catalysts reducibility. Numerous investigations demonstrated that reduction profile of ceria contains two major peaks, one at lower temperature (around $500{ }^{\circ} \mathrm{C}$ ), corresponding to the reduction of surface oxygen of ceria, and one at higher temperature (around $800{ }^{\circ} \mathrm{C}$ ), attributed to the removal of bulk oxygen from the ceria structure. The promotion of ceria by noble $(\mathrm{Au}, \mathrm{Pt}, \mathrm{Pd}, \mathrm{Rh})$ or transition metals $(\mathrm{Cu}$, $\mathrm{Ni}$ ) facilitates $\mathrm{Ce}^{4+}$ reduction. The first reduction peak is usually shifted to much lower temperature. The TPR profiles at the temperature interval of interest for WGS performance (up to $400{ }^{\circ} \mathrm{C}$ ) are presented in Fig. 2. The effect of nanosized gold to enhance ceria reduction is well demonstrated (Fig. 2 A). The peaks of gold-based catalysts have a complex shape with welldefined maximum and shoulder at high-temperature side. The second component is better expressed in the profile of $\mathrm{Au} / 2.5 \mathrm{YCe}$. The low temperature component could be assigned to the removal of oxygen species with improved mobility due to doping with $\mathrm{Y}_{2} \mathrm{O}_{3}$, accepting the same effect of gold in all samples due to the similar gold dispersion. The high temperature component at around $122{ }^{\circ} \mathrm{C}$ is in the range of $\mathrm{T}_{\max }$ of ceria surface reduction in the undoped Au/Ce sample. Significant differences in the position of $\mathrm{T}_{\max }$ in TPR profiles of all catalysts resulting from the $\mathrm{Y}$-dopant content were not observed. However, the shift to the lowest temperature was registered in the profile of $\mathrm{Au} / 5 \mathrm{YCe}$ sample. 

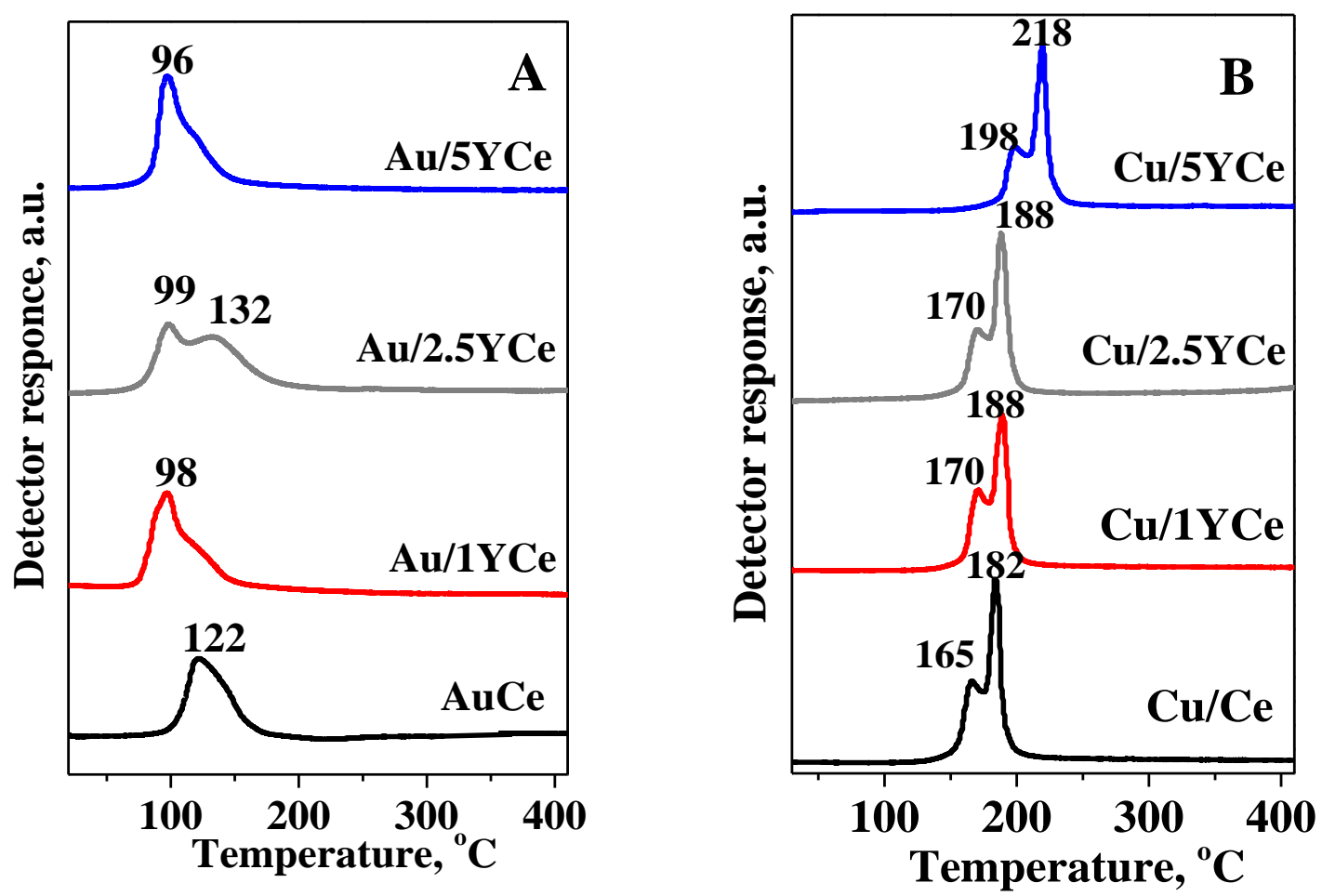

Fig. 2. TPR profiles of gold-based catalysts (A) and of copper-based catalysts (B).

The reduction behaviour of $\mathrm{CuO} / \mathrm{CeO}_{2}$ catalysts is widely studied in the literature [20]. The effect of various factors like content of $\mathrm{CuO}$, particles size of ceria and $\mathrm{CuO}$, preparation method, thermal treatment and s.o., on the reducibility have been reported [21]. Firstly, it should be noted that the reduction of bulk $\mathrm{CuO}$ proceeds in a single step process with $\mathrm{T}_{\max }$ at about $300{ }^{\circ} \mathrm{C}$ [18]. The TPR profiles of copper-based catalysts (Fig. 2 B) consist of complex peak with two components. According to the literature, the low-temperature component is due to the reduction of highly dispersed $\mathrm{CuO}_{\mathrm{x}}$ species and $\mathrm{CuO}$-type clusters, while the high-temperature one is attributed to the reduction of both surface ceria oxygen and larger $\mathrm{CuO}$ particles or $\mathrm{Cu}^{2+}$ incorporated in ceria. In the present study, a significant shift of $\mathrm{T}_{\max }$ to a lower temperature in comparison with that of bulk $\mathrm{CuO}$ evidenced the presence of highly dispersed $\mathrm{CuO}$ particles, in agreement with EPR results. However, in contrast to the above discussed improved reduction behaviour of gold-based catalysts on $\mathrm{Y}$-doped ceria, a tendency of higher $\mathrm{T}_{\max }$ with increasing doping amount of $\mathrm{Y}_{2} \mathrm{O}_{3}$ was observed. An additional evidence for diminished reducibility was the lower hydrogen consumption, indicating lower oxygen availability. Obviously, the reason should be related to the modification effect of $\mathrm{Y}_{2} \mathrm{O}_{3}$. In contrast to ceria ability to shift easily between reduced and oxidized state $\left(\mathrm{Ce}^{4+} \leftrightarrow \mathrm{Ce}^{3+}\right), \mathrm{Y}_{2} \mathrm{O}_{3}$ possess stable oxidation state. On the surface of the catalysts with higher dopant content, the reduction via $\mathrm{Cu}^{2+}-\mathrm{O}_{\mathrm{vac}}-\mathrm{Ce}^{3+}$ complex probably is hindered due to the existence of $\mathrm{Cu}^{2+}-\mathrm{O}_{\mathrm{vac}}-\mathrm{Y}^{3+}$ complex and lower number $\mathrm{Cu}-\mathrm{Ce}$ interface sites, respectively. 


\subsection{Catalyst activity measurements}

Gold- and copper-based catalysts exhibited rather different behaviour in the WGS reaction (Fig. 3). The analysis of WGS tests showed superior performance of gold-based samples in the range $180-220^{\circ} \mathrm{C}$ yielding very high CO conversion degrees $(>95 \%)$. The favourable effect of $\mathrm{Y}_{2} \mathrm{O}_{3}$-doping was clearly demonstrated. The similar catalytic activity of gold catalysts supported on Y-doped ceria was explained with the insignificant differences in the gold particle size among all the samples, evidenced by HRTEM/HAADF measurements. The availability of lower amount mobile surface oxygen observed by $\mathrm{H}_{2}$-TPR measurement of $\mathrm{Au} / 2.5 \mathrm{YCe}$ sample was considered as a reason for the lower WGS activity of this sample in the low-temperature region. Additionally, confirmation of this finding was found by determination of the kinetic parameters of reduction on the basis of the experimental $\mathrm{H}_{2}$-TPR profiles and their simulation [17].
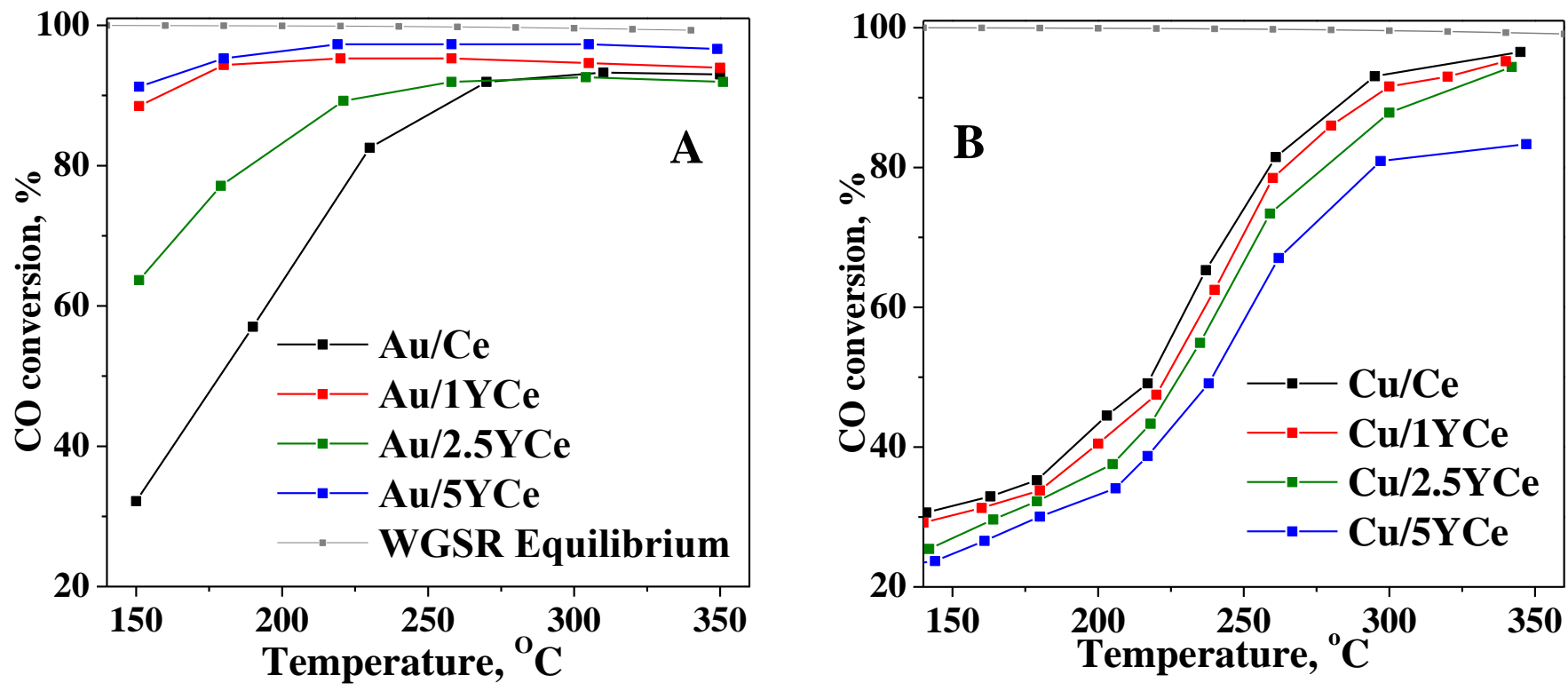

Fig. 3: Temperature dependence of CO conversion over the studied gold-based (A) and copper-based (B) catalysts.

By comparing the beneficial effect of ceria doping with $\mathrm{Y}_{2} \mathrm{O}_{3}$ on gold-catalysed WGS reaction, surprisingly positive role was not observed in copper-based catalysts. In fact, the WGS activity of all samples was very similar, but a trend of decreased $\mathrm{CO}$ conversion over the samples with higher content $\mathrm{Y}_{2} \mathrm{O}_{3}$ was documented. In many cases, the dispersion of metallic particles, formed under WGS conditions, was discussed as responsible for catalytic performance. However, this is not the case in present study, based on XRD and EPR data. Reasonably, the differences in the WGS activity could be related to the catalysts reducibility, e.g. the availability of oxygen species with enhanced mobility.

\section{Conclusion}

Two series catalytic materials were prepared by deposition of gold and copper oxide nanoparticles on ceria doped by various content of $\mathrm{Y}_{2} \mathrm{O}_{3}(1.0,2.5$ and $5.0 \mathrm{wt} . \%)$. A systematic characterization of the catalysts by $\mathrm{N}_{2}$ physisorption, XRD, HRTEM/HAADF, XPS, EPR and $\mathrm{H}_{2}$-TPR shed light on the effect of dopant amount on the WGS performance. Very high $\mathrm{CO}$ conversion was measured after addition of gold, while modification by copper oxide improved the activity at relatively high temperature. The availability of highly dispersed gold nanoparticles with similar average size was suggested to play a role in the high WGS activity of all gold/Y-doped ceria catalysts, with slight superiority of the sample on ceria modified with $5 \mathrm{wt} . \% \mathrm{Y}_{2} \mathrm{O}_{3}$. In contrast, a tendency of decreased $\mathrm{CO}$ conversion over all copper-based samples was observed at increasing content of $\mathrm{Y}_{2} \mathrm{O}_{3}$. The differences in the WGS activity of both gold-and copper-based catalysts were related to the catalysts 
reducibility, highlighting the promotional role of nanosized gold particles to modify stronger the reduction properties of ceria. Additionally, the doping with $\mathrm{Y}_{2} \mathrm{O}_{3}$ of Au/ceria contributed to enhanced mobility of oxygen species. The analysis of structure-property-WGS activity relationship implies that rational changes in the catalyst composition and structure could be a reliable tool for the improvement of catalyst performance.

\section{Acknowledgements}

Authors affiliated at Institute of Catalysis, Bulgarian Academy of Sciences gratefully acknowledge financial support by the Bulgarian National Science Fund (Contract DN 09/5/2016). R. Zanella acknowledges the financial support granted by PAPIIT-UNAM (IN103719) and APN-CONACYT (1216) and the technical support provided by V. Maturano.

\section{References}

[1] S. J. Roberts, J. V. Fletcher, Y .Zhou, N. T. J. Luchters, J. C .Q. Fletcher, "Water-gas shift of reformate streams over mono-metallic PGM catalysts," Int. J. Hydrogen Energy, vol. 43, no. 12, pp. 6150-6157, 2018.

[2] J. H. Carter, G. J. Hutchings, "Recent advances in the gold-catalysed low-temperature water-gas shift reaction," Catalysts, vol. 8, pp. 627-15, 2018.

[3] D. Andreeva, V. Idakiev, T. Tabakova, A. Andreev, "Low-temperature water-gas shift reaction over $\mathrm{Au} / \mathrm{a}-\mathrm{Fe}_{2} \mathrm{O}_{3}$ ", $J$. Catal., vol. 158, pp. 354-355, 1996.

[4] R. Burch, "Gold catalysts for pure hydrogen production in the water-gas shift reaction: activity, structure and reaction mechanism," Phys. Chem. Chem. Phys., vol. 8, pp. 5483-5500, 2006.

[5] T. Ramirez Reina, M. González, S. Palma, S. Ivanova, J. A. Odriozola, "Twenty years of golden future in the water gas shift reaction" in Heterogeneous gold catalysts and catalysis, Z. Ma and S. Dai, Eds. Cambridge: The Royal Society of Chemistry, UK, 2014, pp.111-139.

[6] T. Tabakova, L. Ilieva, I. Ivanov, R. Zanella, J. W. Sobczak, W. Lisowski, Z. Kaszkur, D. Andreeva, "Influence of the preparation method and dopants nature on the WGS activity of gold catalysts supported on doped by transition metals ceria," Appl. Catal. B, vol. 136-137, pp. 70-80, 2013.

[7] T. Tabakova, V. Idakiev, J. Papavasiliou, G. Avgouropoulos, T. Ioannides, "Effect of additives on the WGS activity of combustion synthesized $\mathrm{CuO} / \mathrm{CeO}_{2}$ catalysts," Catal. Commun., vol. 8, pp. 101-106, 2007.

[8] G. K. Williamson, W. H. Hall, "X-ray line broadening from filed aluminium and wolfram," Acta Metallurg., vol. 1, 22-31, 1953.

[9] V. D. Mote, Y. Purushotham, B. N. Dole, "Williamson-Hall analysis in estimation of lattice strain in nanometer-sized ZnO particles," J. Theor. Appl. Phys., vol. 6, pp. 6-28, 2012.

[10] E. Beche, G. Peraudeau, V. Flaud, D.Perarnau, "An XPS investigation of $\left.\left(\mathrm{La}_{2} \mathrm{O}_{3}\right)_{1-\mathrm{x}}\left(\mathrm{CeO}_{2}\right)_{2 \times} \mathrm{ZrO}_{2}\right)_{2}$ compounds.," Surf. Interface Anal., vol. 44, pp. 1045-1050, 2012.

[11] J. Tan, W. Zhang, Y.H. Lv, A.L. Xia, "Facile preparation of Mn-doped $\mathrm{CeO}_{2}$ submicrorods by composite-hydroxidesalt-mediated approach and their magnetic property," Mat. Res., vol. 16, pp. 689-694, 2013.

[12] N. Kotzev N, D. Shopov, "A thermodesorption study of the system olefin - NiO”, J. Catal., vol. 22. pp. 297-301, 1971.

[13] D. A. M. Monti, A. Baiker, "Temperature-programmed reduction, parametric sensitivity and estimation of kinetic parameters," J. Catal., vol. 83, pp. 323-335, 1983.

[14] S. R. Bishop, D. Marrocchelli, C. Chatzichristodoulou, N. H. Perry, M. B. Mogensen, H. L. Tuller, E. D. Wachsman, "Chemical expansion: implications for electrochemical energy storage and conversion devices," Annu. Rev. Mater. Res., vol. 44, pp. 205-239, 2014.

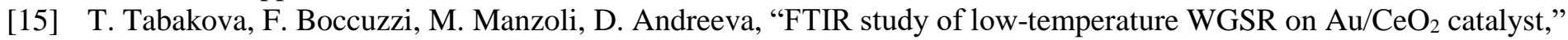
Appl. Catal. A, vol. 252, pp. 385-397, 2003.

[16] D. Andreeva, V. Idakiev, T. Tabakova, A. Andreev, "Low-temperature water-gas shift reaction over $\mathrm{Au} / \mathrm{a}-\mathrm{Fe}_{2} \mathrm{O}_{3}$," $J$. Catal., vol. 158, pp. 354-355, 1996. 
[17] G. Munteanu, P. Petrova, I. Ivanov, L. F. Liotta, Z. Kaszkur, T. Tabakova, L. Ilieva, "Temperature programmed reduction of lightly yttrium-doped $\mathrm{Au} / \mathrm{CeO}_{2}$ catalysts: correlation between oxygen mobility and WGS activity," $J$. Therm. Anal. Calorim., vol. 131, pp. 145-154, 2018.

[18] J. Papavasiliou, G. Avgouropoulos, T. Ioannides, "Combined steam reforming of methanol over $\mathrm{Cu}-\mathrm{Mn}$ spinel oxide catalysts," J. Catal., vol. 251, pp. 7-20, 2007.

[19] P. Ratnasamy, D. Srinivas, C. V. V. Satyanarayana, P. Manikandan, R. S. Senthil Kumaran, M. Sachin, V. N. Shetti, "Influence of the support on the preferential oxidation of $\mathrm{CO}$ in hydrogen-rich steam reformates over the $\mathrm{CuO}_{-} \mathrm{CeO}_{2}$ $\mathrm{ZrO}_{2}$ system," J. Catal., vol. 221, pp. 455-465, 2004.

[20] G. Avgouropoulos, T. Ioannides, "Selective $\mathrm{CO}$ oxidation over $\mathrm{CuO}-\mathrm{CeO}_{2}$ catalysts prepared via the urea-nitrate combustion method," Appl. Catal. A, vol. 244, pp. 155-167, 2003.

[21] M. Konsolakis, "The role of copper-ceria interactions in catalysis science: Recent theoretical and experimental advances," Appl. Catal. B, vol. 198, pp 49-66, 2016. 